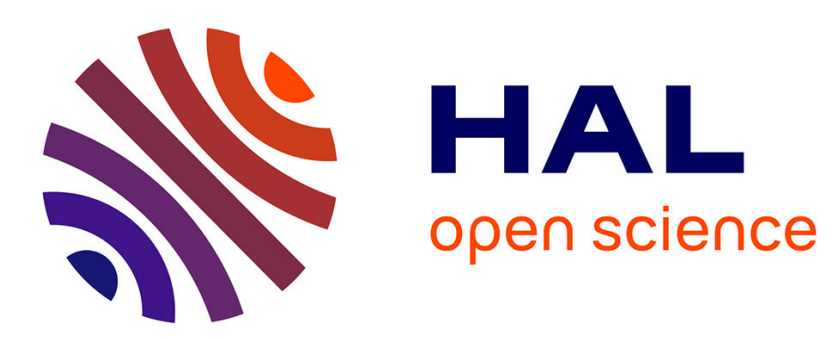

\title{
Guiding the synthesis of pentazole derivatives and their mono- and di-oxides with quantum modeling Gilles Frison, Guy Jacob, Gilles Ohanessian
}

\section{To cite this version:}

Gilles Frison, Guy Jacob, Gilles Ohanessian. Guiding the synthesis of pentazole derivatives and their mono- and di-oxides with quantum modeling. New Journal of Chemistry, 2013, 37, pp.611-618. $10.1039 / \mathrm{c} 2 \mathrm{nj} 40649 \mathrm{~g}$. hal-00761248

\section{HAL Id: hal-00761248 \\ https://hal.science/hal-00761248}

Submitted on 5 Dec 2013

HAL is a multi-disciplinary open access archive for the deposit and dissemination of scientific research documents, whether they are published or not. The documents may come from teaching and research institutions in France or abroad, or from public or private research centers.
L'archive ouverte pluridisciplinaire HAL, est destinée au dépôt et à la diffusion de documents scientifiques de niveau recherche, publiés ou non, émanant des établissements d'enseignement et de recherche français ou étrangers, des laboratoires publics ou privés. 
Guiding the synthesis of pentazole derivatives and their mono- and dioxides with quantum modeling.

\author{
Gilles Frison, ${ }^{*, a}$ Guy Jacob, ${ }^{*, b}$ Gilles Ohanessian, ${ }^{* a}$
}

a : Laboratoire des Mécanismes Réactionnels, Ecole Polytechnique, CNRS, 91128 Palaiseau, France

b : Herakles, Centre de Recherches du Bouchet, 9 rue Lavoisier, 91710 Vert-le-Petit, France

e-mail address: gilles.frison@ @olytechnique.org (G.F.); g.jacob@safran-sme.fr (G.J.);

gilles.ohanessian@polytechnique.fr (G.O.). 


\begin{abstract}
There is high prospect that derivatives of pentazole can lead to high energy density materials. However these molecules are potentially hazardous because of their high formation enthalpies and weak N-N bonds. In order to devise efficient protocols, possible schemes for the synthesis of nitro and azido derivatives of pentazole, and their mono- and di-oxides, have been explored using quantum chemical methods. Reaction pathways have been investigated in details, with particular emphasis on locating transition states and on obtaining a reliable treatment of solvent effects. Oxidation by ozone is found to be a favorable process, leading to some regioselectivity in favor of $\beta$-mono-oxides. Nitration by $\mathrm{NO}_{2}{ }^{+} \mathrm{BF}_{4}{ }^{-}$is also predicted to be favorable. On the contrary the electrochemical azidation of $\mathrm{N}_{5}{ }^{-}$and its oxydized derivatives is found to be energetically inaccessible. Combination of the individual addition and oxidation steps leads to recommendations for future synthetic work. Finally the kinetic stability of products with respect to $\mathrm{N}_{2}$ and $\mathrm{N}_{2} \mathrm{O}$ elimination is assessed.
\end{abstract}

\title{
Keywords
}

High energy density materials (HEDM); Density functional theory (DFT); micro-solvation; nitrogen; ozone; nitration. 


\section{Introduction}

Molecules with high formation enthalpies have long been used as building blocks of energetic materials with applications in several different areas. Future applications of the chemistry of energetic materials are envisaged in the fields of space and defense for propulsion of rockets. The task is to increase the impulse to achieve higher payloads and get access to long term missions that are inconceivable with currently available ingredients. Thus increasing the energy content of constituent molecules remains a recurring concern. Changes in the nature of energetic groups (nitroesters, nitroaromatics, nitramines) during the last 150 years have led to continuous performance improvement, however with limited gain at each step. For more than 20 years, ${ }^{1}$ the concept of High Energy Density Materials (HEDM) has appeared as leading to very high performance energetic molecules for applications in both explosives and rocket propellants. Calculations predict large improvements in both impulse and detonation energy. In conventional energetic molecules (EM), the energy is released from the decomposition of the molecule into oxidized forms of carbon and hydrogen using the oxygen that is present in the molecule (or in the formulation). In addition to the energy release due to the high heat of formation of the parent molecule, the light gases are generated at high temperature and expelled in large volume, producing the desired mechanical effect. HEDM differ from EM in that no oxidation process is necessary as far as the compound would be composed of light atoms linked by weak bonds (achieving high heat of formation) and able to recompose into light molecules containing stronger bonds. ${ }^{2,3}$ Nitrogen is the element of choice for such compounds due to the large difference of bond energies between weak N-N single bonds present in polyatomics and the very strong triple bond of dinitrogen. Elaboration of structures according to this principle is still a challenge for chemists as no such structures are known and as the basic knowledge of this chemistry is scarce. Although no systematic procedure for designing these compounds has been published, a large body of literature describes the computed properties of the virtual polynitrogen structures. ${ }^{4,5}$ Isolation of $\mathrm{N}_{5}{ }^{+}$salts $^{6}$ and detection of $\mathrm{N}_{4}{ }^{7}$ and $\mathrm{N}_{5}{ }^{-8,9}$ in mass spectrometers have given trust in the feasibility of HEDM chemistry.

Increased stability of cyclic polynitrogen molecules can be achieved by the introduction of oxygen atom(s) either as part of the cycle or exocyclically as nitroxide bonds. ${ }^{10,11}$ The pentazolate anion looks as a precursor of choice for HEDM not only because arylpentazoles have been known for a long time and because the heterolytic breaking of the aryl-pentazole bond has been suggested, ${ }^{12,13}$ but also because pentazolate anions have already been synthesized as zinc salt. ${ }^{14}$ 
During the course of our study on isolation of HEDM molecules, we have examined several synthetic routes to nitro and azido derivatives of pentazole mono- and di-oxides as stabilized analogues of the elusive pentazolate. Ozone and nitronium tetrafluoroborate have been selected as reactants for oxidation and nitration, respectively, because the cleanliness of the reactions makes them suitable for first experimental work. A number of these routes have been characterized by quantum chemical calculations of the various minima and transition states along various pathways. In this paper, we summarize the results of these investigations as well as the assessment of the kinetic stability of the target products.

\section{Computational methods}

In this paper we describe results obtained using a well established quantum chemical methodology, the B3LYP hybrid density functional associated with the valence double- $\zeta 6$ $31 \mathrm{G}(\mathrm{d})$ basis set, including polarization functions on all atoms except $\mathrm{H}$, for geometry optimization. In some cases the diffuse-augmented $6-31+\mathrm{G}(\mathrm{d})$ basis set was used; this is specified in the associated text. Improved energies were obtained by single-point calculations at the B3LYP level, with the extended basis set of polarized valence triple- $\zeta$ quality 6$311+\mathrm{G}(2 \mathrm{~d}, 2 \mathrm{p})$. It has been shown that the B3LYP barrier heights could be underestimated for the decomposition of nitrogen-oxygen compounds. ${ }^{15}$ Therefore, final energy calculations at the $\operatorname{CCSD}(\mathrm{T})$ level associated with the aug-cc-pVDZ or aug-cc-pVTZ basis sets have been achieved for selected key structures, to check our DFT results. In all cases except one (vide infra), trends observed for CCSD(T) calculations are well reproduced by B3LYP.

Some care has been taken to provide a realistic modeling of solvent effects. Solvation free energy corrections were determined using the polarizable continuum solvation model CPCM. In the most simple implementation, the CPCM calculations were carried out on the gas phase B3LYP/6-31G(d) geometries, at the B3LYP/6-311+G(2d,2p) level, with a dielectric constant $\varepsilon$ of $35.688,32.613$ and 78.3553 for acetonitrile, methanol and water, respectively. Refined models were built by adding a variable number of solvent molecules, described at the same DFT level as the solutes. The number of explicit solvent molecules was determined so as to provide a first solvation sphere to the solutes and to obtain a balanced description of reaction thermodynamics. In order to provide a reliable comparison between explicitly solvated reactants, transition states (TS) and products, the following modeling strategy has been applied: (a) explicit solvent molecules are manually added around the gas phase TS and their 
positions are computationally optimized keeping frozen the geometry of the solute, making sure that a chemically meaningful solvation of the solute is maintained; (b) a geometry optimization without constraint is achieved, leading to the explicitly solvated TS; (c) forward and reverse IRC calculations are performed to locate explicitly solvated reactant and product including comparable position of solvent molecules. The resulting systems were then treated with the same CPCM approach as above for the bare solutes. All calculations have been performed with Gaussian $03 .^{16}$

\section{Results and discussion}

Starting from pentazolate $\mathbf{1}$, the synthesis of nitro- and azido-pentazole- $N$-oxide 5-8 can be envisioned by introducing first either the oxygen atom or the nitro/azido group (Scheme 1).

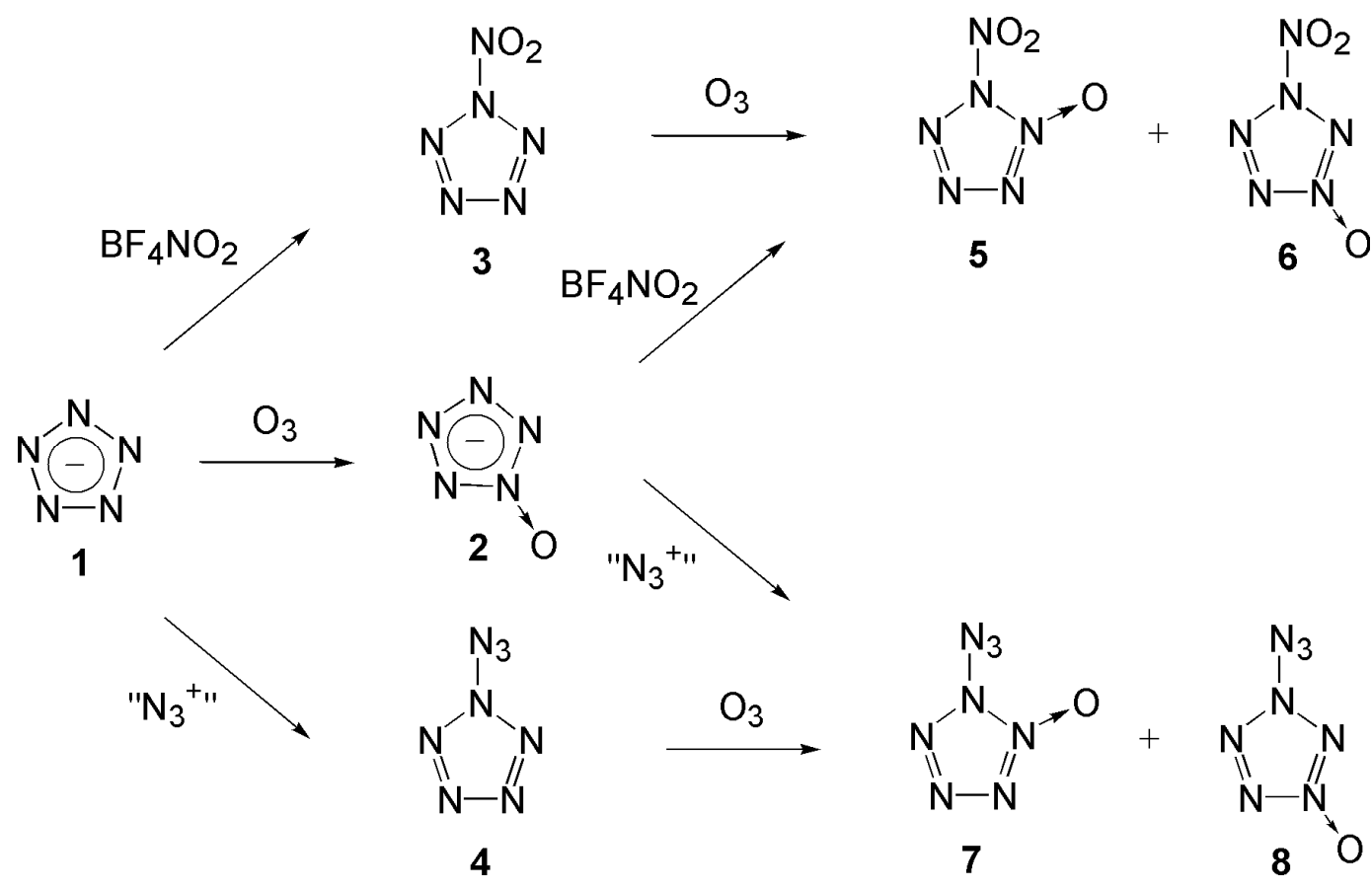

Scheme 1. Envisioned pathways from pentazolate anion to nitro- and azido-pentazole- $N$ oxide.

These pathways have been studied theoretically at the DFT level in order to evaluate the feasibility of these synthetic routes, and determine the easiest one. The envisioned nitrating agent is $\mathrm{BF}_{4} \mathrm{NO}_{2}$ whereas the introduction of the azide substituent is planned through an electrochemical pathway. The chemical oxidation may be achieved with ozone, as demonstrated with nitrotetrazolate ${ }^{17 \mathrm{a}}$ and azidotetrazolate. ${ }^{17 \mathrm{~b}}$ A second oxidation step, leading 
to compounds 9-14, and the oxidation of phenylpentazole $\mathbf{1 5}$, precursor of $\mathbf{1}$, have also been studied. Nitrotetrazolate 18 and azidotetrazolate $\mathbf{2 1}$ have been considered as well, for comparison with experimental data. ${ }^{17}$ This leads to the series of compounds shown in Scheme 2. Finally, the kinetic stability of some of these mono- and di-oxidized synthetic targets has been explored.
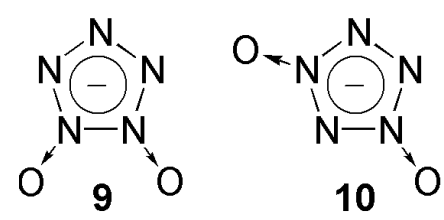<smiles>c1ccccc1</smiles>

15<smiles>Nc1nn[nH]n1</smiles>

21<smiles></smiles>

16<smiles>Nc1nnnn1O</smiles>

22<smiles>NN1N(O)N=NN1O</smiles>

11<smiles></smiles>

17<smiles></smiles>

12<smiles>O=[N+]([O-])c1nn[nH]n1</smiles>

18<smiles></smiles><smiles></smiles>

14<smiles>O=[N+]([O-])c1nnn(O)n1</smiles><smiles>Cn1nnc(N)n1</smiles>

23

Scheme 2. Other compounds derived from pentazole (9-17) and tetrazole (18-23) studied in this work. 


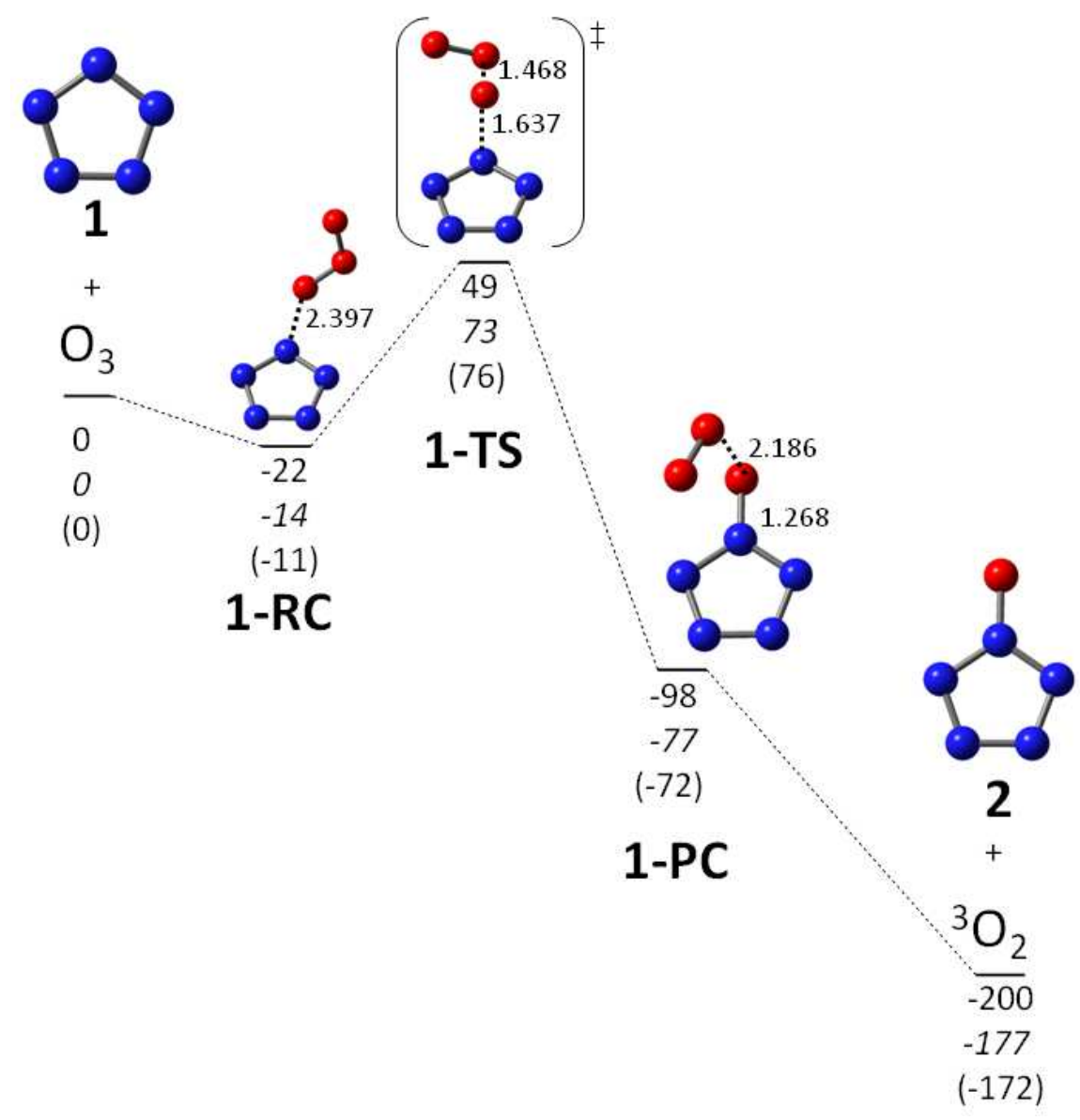

Figure 1. Potential energy surface $(\mathrm{kJ} / \mathrm{mol})$ of oxygen atom transfer from $\mathrm{O}_{3}$ to 1 computed at the B3LYP/6-311+G(2d), CCSD(T)/aug-cc-pVDZ (italics) and CCSD(T)/aug-cc-pVTZ (in parentheses) levels using B3LYP/6-31G(d) geometries.

\section{Chemical oxidation by ozone}

As a first step of our study, we have examined the oxidation mechanism of unsaturated nitrogen compounds by ozone. It is well known that ozonolysis of alkenes and alkynes leads to various oxidized compounds such as ketones, aldehydes or epoxides. ${ }^{18}$ The main proposed mechanism involves as first step a 1,3-dipolar cycloaddition of ozone with the unsaturated bond leading to cyclic $\mathrm{C}_{2} \mathrm{O}_{3}$ ozonide. ${ }^{19}$ Such a pathway has been searched for starting from $\mathbf{1}$ and 3, however no intermediate including a $\mathrm{N}_{2} \mathrm{O}_{3}$ ring could be obtained. Such structures lead in all cases either to separated reactants $\mathrm{O}_{3}$ and $\mathbf{1 / 3}$, or to the disruption of the $\mathrm{N}_{5}$ ring. Exploring other pathways, it was possible to locate a transition state corresponding to the transfer of one oxygen atom to the pentazole and the released of $\mathrm{O}_{2}$. The associated potential energy profile starting from $\mathbf{1}$ is depicted in Figure 1. Starting from the separated reactants 1 and $\mathrm{O}_{3}$, an intermediate 1-RC (Reactant Complex) is formed in the gas phase. This weak interaction between the reactants implies only one nitrogen atom of the ring and one terminal 
oxygen of ozone. This oxygen atom is then transferred to one nitrogen atom of the ring, through transition state 1-TS, forming a complex (called 1-PC for Product Complex) between $\mathbf{2}$ and singlet dioxygen. In this intermediate, $\mathrm{O}_{2}$ interacts not only with the oxygen atom of $\mathbf{2}$, but also with the $\mathrm{N}_{5}$ ring, as indicated by its position above the ring. Final dissociation of 1PC to form the target product $\mathbf{2}$ may be accompanied by stabilization of dioxygen to its triplet ground state, leading to a high reaction exothermicity $(200 \mathrm{~kJ} / \mathrm{mol}$ at the B3LYP level).

It is known that ozone has a partial biradical character and that restricted and unrestricted DFT may give different results. UB3LYP calculation of 1-TS confirms that the TS structure and its energy relative to $\mathbf{1}+\mathrm{O}_{3}$ are only slightly influenced by the closed vs. open shell description. Therefore, we have restricted the following investigations to RDFT calculations. The reliability of this approach has been further confirmed by its agreement with experiment ${ }^{17}$ on the regioselectivity of the oxidations of $\mathbf{1 8}$ and $\mathbf{2 1}$ (vide infra). In addition, the activation energies reported for these reactions in Table 2 are fully compatible with reactions carried out at $40{ }^{\circ} \mathrm{C}{ }^{17}$

Due to the anionic nature of $\mathbf{1}$, it can be hypothesized that solvation would significantly modify the potential energy surface of this reaction. We have therefore included solvation effects through the introduction of explicit solvent molecules during the geometry optimization process and with the conductor-polarized continuum method (CPCM) for final energy calculations. In 1-RC, 1-TS and 1-PC, we have therefore added five acetonitrile molecules in order to solvate the pentazolate anion fragment only and eleven to solvate the full system. The structures of the corresponding TS are depicted in Figure 2.

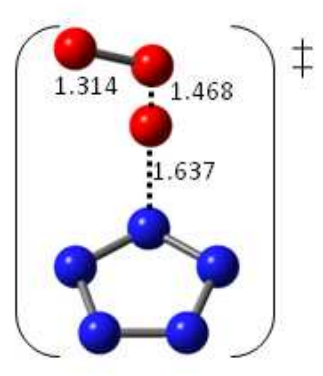

1-TS

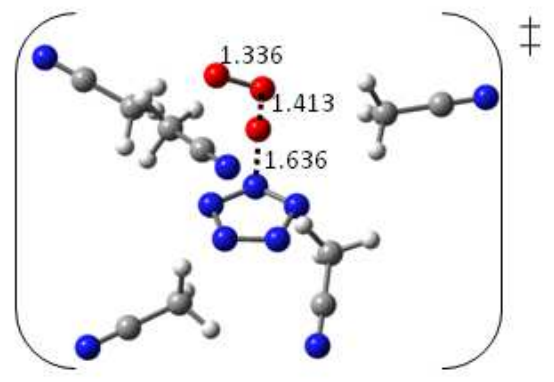

1-TS $\left(\mathrm{CH}_{3} \mathrm{CN}\right)_{5}$

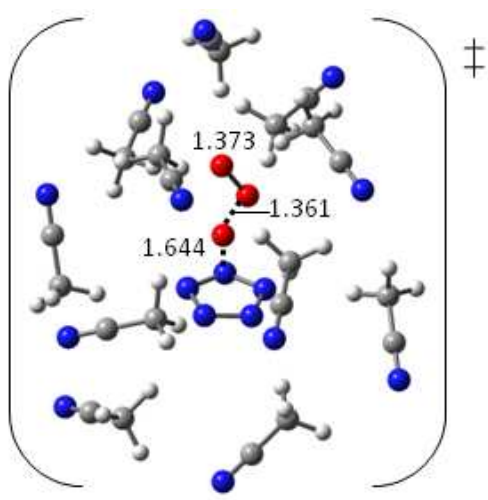

1-TS $\left(\mathrm{CH}_{3} \mathrm{CN}\right)_{11}$

Figure 2. Geometry optimized structures of the transition state for the transfer of oxygen atom between ozone and pentazolate including various numbers of explicit solvent molecules. 
The inclusion of acetonitrile molecules does not influence the interaction between the two reaction partners nor the formation of the $\mathrm{N}-\mathrm{O}$ bond as indicated by the $\mathrm{N}{ }^{\cdots} \mathrm{O}$ distance in the transition states. On the contrary, the elongated $\mathrm{O} \cdots \mathrm{O}$ bond is sensitive to the solvent description (1.468, 1.413 and $1.361 \AA$ in 1-TS, 1-TS $\left(\mathrm{CH}_{3} \mathrm{CN}\right)_{5}$ and 1-TS $\left(\mathrm{CH}_{3} \mathrm{CN}\right)_{11}$, respectively), indicating that solvation induces an earlier TS with a less pronounced dissociated character of ozone.

Table 1. Relative energies (in $\mathrm{kJ} / \mathrm{mol}$ ) for the reaction between ozone and $\mathbf{1}$ with various solvation schemes.

\begin{tabular}{ccccc}
\hline $\begin{array}{c}\text { Number of explicit } \\
\text { solvent molecule }^{\mathrm{a}}\end{array}$ & $\begin{array}{c}\text { Implicit }^{\text {solvation }}{ }^{\mathrm{b}} \\
\text { sol-RC }^{\mathrm{c}}\end{array}$ & $\mathbf{1 - T S}^{\mathrm{c}}$ & $\mathbf{1 - P C}^{\mathrm{c}}$ \\
\hline 0 & No & 0 & $71(87)$ & $-75(-64)$ \\
0 & Yes & 0 & $68(84)$ & $-78(-66)$ \\
5 & No & 0 & 61 & -80 \\
5 & Yes & 0 & 64 & -76 \\
11 & No & 0 & 58 & -64 \\
11 & Yes & 0 & 74 & -70 \\
\hline
\end{tabular}

${ }^{a}$ Solvent molecules (acetonitrile) included during the geometry optimization process at the B3LYP/6-31G(d) level. ${ }^{b}$ Inclusion of the CPCM (acetonitrile. $\varepsilon=35.688$ ) implicit solvation scheme for the final energy calculations at the B3LYP/6-311+G(2d,2p) level. ${ }^{c}$ Relative energy computed at the B3LYP/6-311+G(2d,2p) and CCSD(T)/aug-cc-pVDZ (in parentheses) levels using B3LYP/6-31G(d) geometries.

However, values in Table 1 indicate that the energy barrier and the exothermicity of the oxidation reaction are only slightly influenced by solvation. Indeed, similar results are obtained with or without polarizable continuum, as well as with or without explicit solvent molecules. Consequently, explicit solvent molecules were not included in the other oxidation reactions with ozone described below. 
Table 2. Oxidation energies of tetra- and pentazole derivatives.

\begin{tabular}{|c|c|c|c|}
\hline \multirow[t]{2}{*}{ Reactant } & \multirow{2}{*}{$\begin{array}{c}\text { Transition state } \\
\mathrm{E}_{\text {rel }}^{\mathrm{b}}\end{array}$} & \multicolumn{2}{|c|}{ Product $^{\mathrm{a}}$} \\
\hline & & $\mathrm{E}_{\mathrm{rel}}^{\mathrm{b}}$ & number \\
\hline 2 & $+105(+126)$ & $-157(-129)$ & 9 \\
\hline 2 & $+86(+108)$ & $-181(-156)$ & 10 \\
\hline 3 & $+178(+158)$ & $-128(-103)$ & 5 \\
\hline 3 & $+156(+139)$ & $-169(-139)$ & 6 \\
\hline 4 & $+178(+152)$ & $-140(-121)$ & 7 \\
\hline 4 & $+153(+133)$ & $-163(-135)$ & 8 \\
\hline 7 & $+159(+124)$ & $-145(-128)$ & 11 \\
\hline 8 & $+162(+137)$ & $-136(-123)$ & 12 \\
\hline 8 & $+170(+143)$ & $-138(-131)$ & 13 \\
\hline 8 & $+172(+128)$ & $-112(-94)$ & 14 \\
\hline 15 & +171 & -141 & 16 \\
\hline 15 & +140 & -168 & 17 \\
\hline 18 & +81 & -169 & 19 \\
\hline 18 & +72 & -205 & 20 \\
\hline 21 & +54 & -178 & 22 \\
\hline 21 & +46 & -207 & 23 \\
\hline
\end{tabular}

${ }^{\mathrm{a}}$ Separated products with dioxygen in its triplet state. ${ }^{\mathrm{b}}$ relative energy (related to separated reactants) in $\mathrm{kJ} / \mathrm{mol}$ computed at the B3LYP/6-311+G(2d,2p) and CCSD(T)/aug-cc-pVDZ (in parentheses) levels using B3LYP/6-31G(d) geometries, including CPCM(acetonitrile) solvation correction obtained at the B3LYP/6-311+G(2d,2p) level.

Following this study on the mono-oxidation of $\mathbf{1}$, we explored the same process starting from various tetra- and pentazole derivatives (Table 2). In all cases, the same oxygen transfer mechanism has been obtained. Comparison between the TS geometries indicates a stronger interaction of the $\mathrm{O}_{2}$ leaving group with the ring for neutral substituted pentazoles $(\mathbf{3}, \mathbf{4}, \mathbf{7}, \mathbf{8}$, and 15) than for anionic pentazolates (1 and 2) and tetrazolates (18 and $\mathbf{2 1})$. This difference in geometry parallels a higher reactivity for the anions, as revealed by the relative energies of the TS. Surprisingly, B3LYP barriers are underestimated for anions and overestimated for neutrals, compared to $\operatorname{CCSD}(\mathrm{T})$ values. However, these quantitative differences do not modify the relative reactivity between anions and neutrals. A closer examination indicates that phenylpentazole (15) is slightly more reactive than nitro- (3) and azidopentazole (4). 
Similarly, azidotetrazolate (21) is more reactive than nitrotetrazolate (18). The second oxidation of 1 (i.e. the oxidation of 2) is more difficult to achieve than the first. This observation seems to be more questionable for azido-pentazole derivatives. Indeed, contrary to B3LYP values, $\operatorname{CCSD}(\mathrm{T})$ ones indicate that $\mathbf{4}$ is slightly less reactive than $\mathbf{8}$. Taken together, these results show that the reactivity parallels mostly the electronic density located on the nitrogens in the ring, which depends mainly on the electronic charge (anionic vs. neutral compounds) and to a lesser degree on the withdrawing ability of the substituents $\left(\mathrm{NO}_{2}\right.$ $>\mathrm{N}_{3}>\mathrm{Ph} ; \mathrm{O}>$ no substituent). These results also indicate that it could be possible in some cases to stop the reaction after the first oxidation step in order to obtain mono-oxidized products.

For each mono-substituted tetra- and pentazole-based derivative (2, 3, 4, 15, 18 and 21), two isomers may be obtained in principle through $N$-oxidation either in $\alpha$ - or in $\beta$-position relative to the substituent. In all cases, $\beta$-oxidation is found to be easier than $\alpha$-oxidation, both at the B3LYP and CCSD(T) levels, with an energy barrier which is lower by ca. 20-30 and 10-20 $\mathrm{kJ} \mathrm{mol}^{-1}$ for neutrals and anions respectively. This difference seems to be induced by repulsion between the substituent and the incoming azoxy group, which leads phenyl-, nitroand azide substituents not to lie in the $\mathrm{N}_{5}$ or $\mathrm{CN}_{4}$ ring plane. This results announces that oxidation of mono-substituted derivatives is a regioselective (or even regiospecific) process. Furthermore, this kinetic preference for $\beta$-oxidation comes along with thermodynamic preference for the same position, once again due to repulsive interaction between substituents. This theoretical result nicely agrees with experimental ones obtained recently for tetrazolebased derivatives, ${ }^{17}$ which have shown that nitro- and azidotetrazolate are exclusively $\beta$ oxidized by ozone. It also indicates that oxidation of $\mathbf{1}$ and $\mathbf{2}$ would probably proceed smoothly, as observed for $\mathbf{1 8}$ and $\mathbf{2 1}$, whereas harsher conditions would be probably needed for oxidation of neutral pentazole-base derivatives.

Compared to mono-substituted neutral compounds, the second oxidation process of azidopentazole is less selective. Starting from $\mathbf{8}$, the product obtained after oxidation of $\mathbf{4}$, three $N, N$-oxidized azido-pentazoles 12, 13 and 14 may be obtained. The activation barriers to reach the TS's are close $\left(162-172 \mathrm{~kJ}^{-\mathrm{mol}^{-1}}\right.$ at the B3LYP level, $128-143 \mathrm{~kJ} / \mathrm{mol}$ at the $\operatorname{CCSD}(\mathrm{T})$ level). Furthermore, the most stable isomer (13 both for B3LYP and CCSD(T) levels) is not the one obtained under kinetic control (12 at the B3LYP level, 14 at the $\operatorname{CCSD}(\mathrm{T})$ level). Due to the $\beta$-position of azide and azoxy groups in $\mathbf{8}$, the second incoming 
azoxy group is in all cases located in $\alpha$-position relative to (at least) one of the former $\mathrm{N}_{5^{-}}$ substituents. This may explain the lower selectivity of this oxidation, compared to monosubstituted azido compounds.

We have shown that it should be possible to experimentally manage the oxidation of $\mathbf{1 , 3}$ and 4 by ozone in order to obtain 2 and, selectively, $\mathbf{6}$ and $\mathbf{8}$, respectively. The second oxidation process of $\mathbf{2}$ will lead to $\mathbf{1 0}$ selectively, whereas $\mathbf{6}$ and $\mathbf{8}$ would probably produce a mixture of doubly-oxidized products. Further to these encouraging results, we then turn our interest to the synthesis of nitro- and azido-pentazole derivatives (3-8) from 1 or 2.

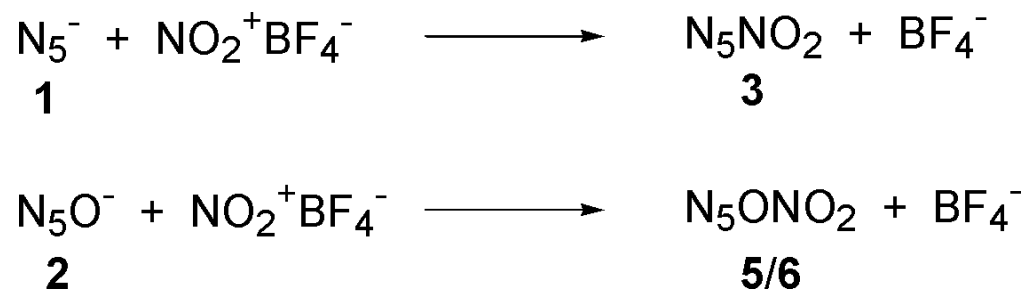

Scheme 3. Nitration process.

\section{Nitration process}

Following the pioneering work of Olah et al., ${ }^{20}$ nitration is commonly carried out through $\mathrm{NO}_{2}{ }^{+}$transfer from the nitronium tetrafluoroborate salt $\mathrm{NO}_{2}{ }^{+} \mathrm{BF}_{4}{ }^{-21}$ Thus it is this reaction which has been envisioned in this work for the nitration of 1 and $\mathbf{2}$ (Scheme 3). B3LYP-DFT calculation in the gas phase indicates that this ion pair is spontaneously transformed into a complex between $\mathrm{BF}_{3}$ and $\mathrm{NO}_{2} \mathrm{~F}$. Thus gas phase modeling is inappropriate in this case. The thermodynamics of reactions 1 and 2 in Scheme 3 have therefore been studied by taking into account solvation in order to obtain a satisfying description of reactants and products. For all compounds $\left(1-3,5,6, \mathrm{NO}_{2}{ }^{+} \mathrm{BF}_{4}^{-}\right.$and $\left.\mathrm{BF}_{4}^{-}\right)$, we have included explicitly several acetonitrile molecules in order to generate a saturated first solvation shell. Due to weak solvent-solvent and solute-solvent intermolecular interactions, a large number of geometry optimizations at the B3LYP/6-31+G(d) level has been achieved for all solutes surrounded by 4 to 7 solvent molecules located in different conformations. From this exploration, we have kept only those structures allowing the same total number of solvent molecules in the reactants and products and those having saturated first solvation shells. Some of these structures are depicted in Figure 3. 
(A)

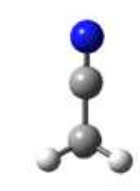

$\cos ^{2}$

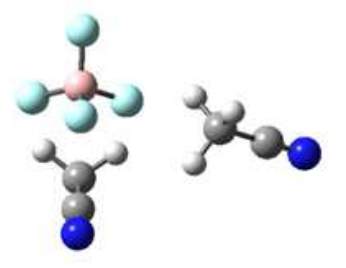

(C)
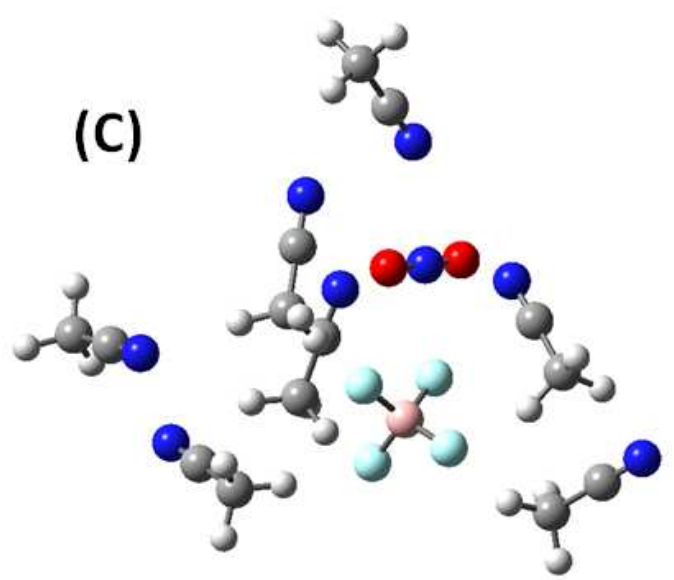

(B)
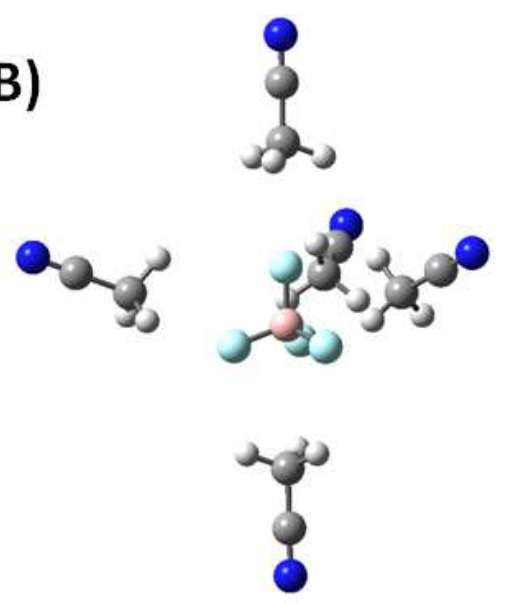

(D)

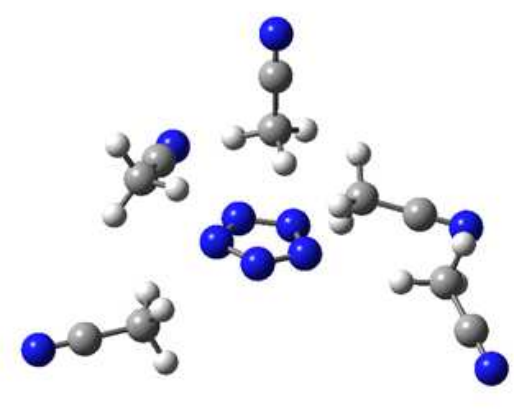

Figure 3. Optimized structures of (A) $\mathrm{BF}_{4}^{-}\left(\mathrm{CH}_{3} \mathrm{CN}\right)_{4}$; (B) $\mathrm{BF}_{4}^{-}\left(\mathrm{CH}_{3} \mathrm{CN}\right)_{5}$; (C) $\mathrm{NO}_{2}{ }^{+} \mathrm{BF}_{4}^{-}$ $\left(\mathrm{CH}_{3} \mathrm{CN}\right)_{7}$; (D) $\mathbf{1}\left(\mathrm{CH}_{3} \mathrm{CN}\right)_{5}$.

It should be noticed that the nitronium salt $\mathrm{NO}_{2}{ }^{+} \mathrm{BF}_{4}^{-}$could only be obtained with at least seven solvent molecules. On the contrary, $\mathrm{N}_{5} \mathrm{NO}_{2}$ is not an ion pair and the $\mathrm{N}-\mathrm{NO}_{2}$ covalent bond is only slightly sensitive to solvation $\left(\mathrm{N}-\mathrm{NO}_{2}=1.51\right.$ and $1.49 \AA$ in the gas phase and in solution, respectively).

The above described micro-solvation scheme allows to examine the nitration reaction including a total of eleven or twelve acetonitrile molecules (Table 3). The computed energies for the nitration of 1 are in all cases negative (between -43 and $-55 \mathrm{~kJ} / \mathrm{mol}$ depending upon the micro-solvation scheme), indicating that a spontaneous process should take place between pentazolate and $\mathrm{NO}_{2}{ }^{+} \mathrm{BF}_{4}^{-}$to form the nitro-pentazole. Furthermore, values obtained with various micro-solvation of solutes are relatively similar, suggesting that the effect of solvation on the thermodynamics of the nitration process has been adequately introduced and that this solvation protocol leads to an error bar of about $15 \mathrm{~kJ} / \mathrm{mol}$ on the thermodynamic of the reaction. The nitration of $\mathrm{N}_{5}{ }^{-}$thus seems to be a synthetically viable process. 
Table 3. Nitration energies (in $\mathrm{kJ} / \mathrm{mol}$ ) computed at the CPCM(acetonitrile)-B3LYP/6$311+\mathrm{G}(2 \mathrm{~d}, 2 \mathrm{p}) / / \mathrm{B} 3 \mathrm{LYP} / 6-31+\mathrm{G}(\mathrm{d})$ level.

\begin{tabular}{llllc}
\hline & Reactants & \multicolumn{2}{c}{ Products } & Nitration energy \\
\hline $\mathbf{1}\left(\mathrm{CH}_{3} \mathrm{CN}\right)_{4}$ & $\mathrm{NO}_{2}{ }^{+} \mathrm{BF}_{4}^{-}\left(\mathrm{CH}_{3} \mathrm{CN}\right)_{7}$ & $\mathrm{BF}_{4}^{-}\left(\mathrm{CH}_{3} \mathrm{CN}\right)_{5}$ & $\mathbf{3}\left(\mathrm{CH}_{3} \mathrm{CN}\right)_{6}$ & -43 \\
$\mathbf{1}\left(\mathrm{CH}_{3} \mathrm{CN}\right)_{4}$ & $\mathrm{NO}_{2}{ }^{+} \mathrm{BF}_{4}^{-}\left(\mathrm{CH}_{3} \mathrm{CN}\right)_{7}$ & $\mathrm{BF}_{4}^{-}\left(\mathrm{CH}_{3} \mathrm{CN}\right)_{4}$ & $\mathbf{3}\left(\mathrm{CH}_{3} \mathrm{CN}\right)_{7}$ & -51 \\
$\mathbf{1}\left(\mathrm{CH}_{3} \mathrm{CN}\right)_{5}$ & $\mathrm{NO}_{2}{ }^{+} \mathrm{BF}_{4}^{-}\left(\mathrm{CH}_{3} \mathrm{CN}\right)_{7}$ & $\mathrm{BF}_{4}^{-}\left(\mathrm{CH}_{3} \mathrm{CN}\right)_{5}$ & $\mathbf{3}\left(\mathrm{CH}_{3} \mathrm{CN}\right)_{7}$ & -55 \\
$\mathbf{2}\left(\mathrm{CH}_{3} \mathrm{CN}\right)_{5}$ & $\mathrm{NO}_{2}{ }^{+} \mathrm{BF}_{4}^{-}\left(\mathrm{CH}_{3} \mathrm{CN}\right)_{7}$ & $\mathrm{BF}_{4}^{-}\left(\mathrm{CH}_{3} \mathrm{CN}\right)_{5}$ & $\mathbf{5}\left(\mathrm{CH}_{3} \mathrm{CN}\right)_{7}$ & +26 \\
$\mathbf{2}\left(\mathrm{CH}_{3} \mathrm{CN}\right)_{5}$ & $\mathrm{NO}_{2}{ }^{+} \mathrm{BF}_{4}^{-}\left(\mathrm{CH}_{3} \mathrm{CN}\right)_{7}$ & $\mathrm{BF}_{4}^{-}\left(\mathrm{CH}_{3} \mathrm{CN}\right)_{5}$ & $\mathbf{6}\left(\mathrm{CH}_{3} \mathrm{CN}\right)_{7}$ & -22 \\
\hline
\end{tabular}

The nitration of $\mathbf{2}$ also leads to an exothermic reaction, however only for the formation of $\mathbf{6}$. This result indicates that the synthesis of $\mathbf{6}$ could be achieved selectively from $\mathbf{2}$, even if the nitration of the latter is more difficult than for $\mathbf{1}$, as there is probably no significant energy barrier for such an ion transfer reaction.

\section{Azidation process}

Following previous experimental studies on azidation of anions, ${ }^{22}$ the synthesis of azidopentazole derivatives has been envisioned electrochemically as illustrated in Scheme 4. It is known from previous studies ${ }^{23,24}$ that the instability of $\mathrm{N}_{5}{ }^{\circ}$ in the gas phase makes this reaction very unlikely starting from $\mathbf{1}$. It is however interesting to consider this synthetic pathway for $\mathbf{2}$ and $\mathbf{1 0}$ since pentazole-oxides are expected to be more stable than pentazole itself. $^{10,11}$

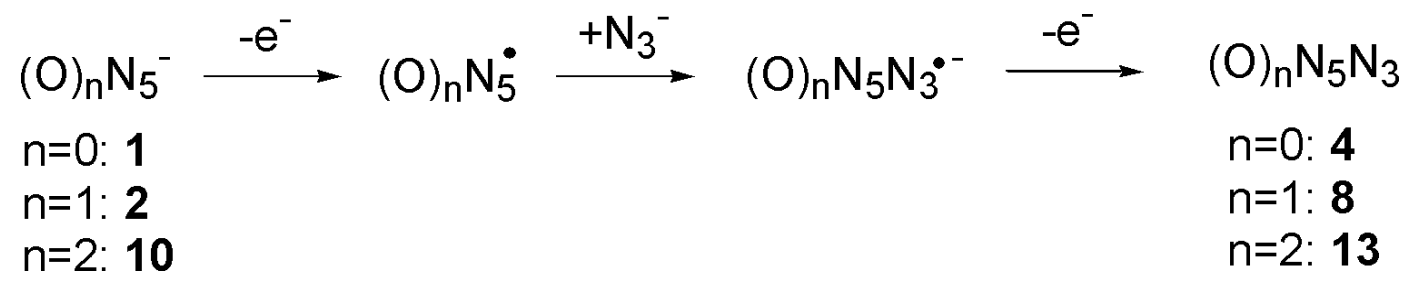

Scheme 4. Electrochemical synthesis of (oxidized) azido-pentazole from (oxidized) pentazolate anion and $\mathrm{N}_{3}^{-}$.

In order to evaluate the feasibility of such a reaction in solution, we have computed the electronic oxidation energy of several nitrogen-based anions. A significant solvent effect is expected on oxidation energies. As an example, oxidation of $\mathrm{N}_{3}^{-}$is known to amount to $263 \pm 12 \mathrm{~kJ} / \mathrm{mol}$ in the gas phase, ${ }^{25}$ a value which is well reproduced by DFT calculations (262 $\mathrm{kJ} / \mathrm{mol}$ ). In solution, at the same level of calculation including solvent effects (see below) this 
value is raised to ca. $520 \mathrm{~kJ} / \mathrm{mol}$ as expected since solvation of the anion is much more stabilizing than that of the neutral radical.

From the results gathered in Table 4, we can conclude that the nature of the solvent does not appear to influence the electronic oxidation energy. Indeed, calculations including a polarizable continuum solvent model lead to almost identical energies for various solvents (acetonitrile, methanol and water). Furthermore, including micro-solvation through explicit solvent molecules does not significantly modify the computed oxidation energies. Therefore, subsequent calculations in this section have been carried out in acetonitrile with the solute surrounded only by a polarizable dielectric continuum.

Table 4. Electronic oxidation energies (in $\mathrm{kJ} / \mathrm{mol}$ ) computed at the CPCM-B3LYP/6$311+\mathrm{G}(2 \mathrm{~d}, 2 \mathrm{p}) / / \mathrm{B} 3 \mathrm{LYP} / 6-31 \mathrm{G}(\mathrm{d})$ level.

\begin{tabular}{cccc}
\hline \multirow{2}{*}{ Molecule } & \multicolumn{3}{c}{ Solvent } \\
\cline { 2 - 4 } & Acetonitrile $(\varepsilon=35.688)$ & Methanol $(\varepsilon=32.613)$ & Water $(\varepsilon=78.3553)$ \\
\hline $\mathbf{1}$ & 732 & 731 & 736 \\
$\mathbf{1 0}$ & 587 & 586 & 590 \\
$\mathrm{~N}_{3}^{-}$ & 557 & 556 & 559 \\
$\mathrm{~N}_{5} \mathrm{~N}_{3}^{\bullet-}$ & 522 & 521 & 526 \\
$\mathbf{1}\left(\mathrm{H}_{2} \mathrm{O}\right)_{5}$ & 400 & 399 & 402 \\
$\mathbf{1}\left(\mathrm{CH}_{3} \mathrm{CN}\right)_{5}$ & - & - & 689 \\
$\mathbf{2}\left(\mathrm{CH}_{3} \mathrm{CN}\right)_{5}$ & 718 & - & - \\
\hline
\end{tabular}

1 has larger oxidation energy than $\mathrm{N}_{3}^{-}$. Therefore, in the presence of $\mathrm{N}_{3}^{-}$, the radical oxidized counterpart of $\mathbf{1}$ would not chemically add to it, but rather an electronic transfer would take place, leading to $\mathrm{N}_{3}^{\bullet}$ and the initial anion 1 (Scheme 5). $N$-oxidized pentazolates 2 and $\mathbf{1 0}$ have lower electronic oxidation energies than 1 (587 and $557 \mathrm{vs} .732 \mathrm{~kJ} / \mathrm{mol}$ in acetonitrile). However, these energies remain larger than the oxidation energy of $\mathrm{N}_{3}{ }^{-}$and the same electronic transfer would also be observed. 
(A)
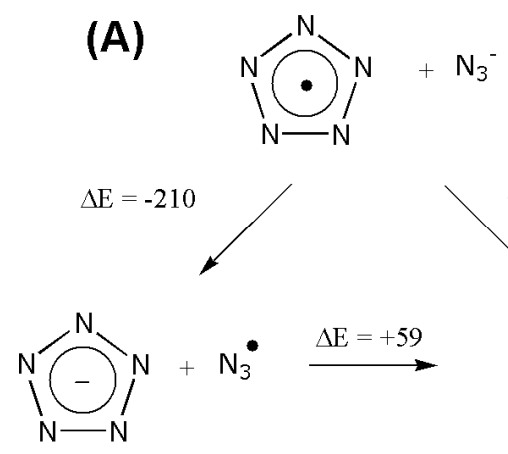

(B)

$\Delta \mathrm{E}=-151$

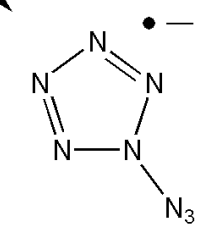

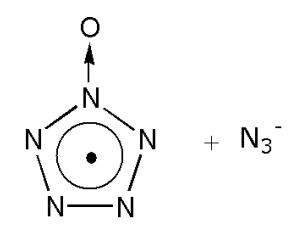

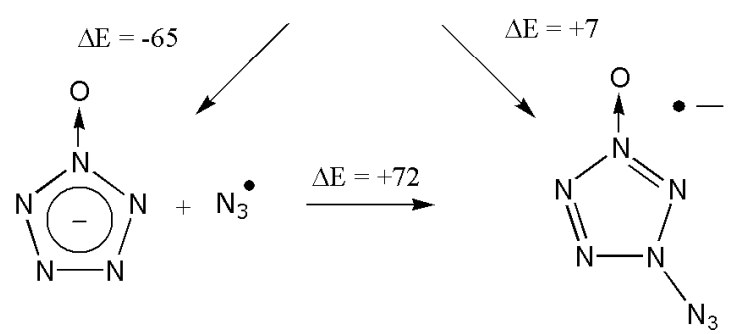

Scheme 5. Energies of the reaction between $\mathrm{N}_{3}{ }^{-}$and (A) 1; (B) 2 .

At this point, a chemical reaction between 1 or 2 and $\mathrm{N}_{3}{ }^{\bullet}$ could be envisioned. However, these reactions are endothermic (Scheme 5). We can thus conclude that the electrochemical synthesis of azido-pentazole derivatives from pentazolate and $\mathrm{N}_{3}{ }^{-}$is thermodynamically impossible. It was further found that $\mathrm{N}_{5} \mathrm{~N}_{3}{ }^{\bullet-}$ and $\mathrm{N}_{5} \mathrm{ON}_{3}{ }^{\bullet-}$ are kinetically instable relative to loss of $\mathrm{N}_{2}$ (from the $\mathrm{N}_{3}$ moiety), with a transition barrier no larger than 14 and $10 \mathrm{~kJ} / \mathrm{mol}$, respectively.

Kinetic stability of pentazole mono- and di-oxide

Even if it has been proposed that an $N$-oxide group kinetically stabilizes pentazolate derivatives, ${ }^{11}$ the interest of the synthetic targets studied in this work as potential candidates for high energy density materials has to be explored. Therefore, we have examined the decomposition paths of 4-8 and 11-13 toward loss of $\mathrm{N}_{2}$ and $\mathrm{N}_{2} \mathrm{O}$. Depending upon the case, these two processes may or may not be competitive. In addition, elimination of $\mathrm{N}_{2}$ may occur in a stepwise or in a concerted manner. The optimized structures obtained for the decompositions of $\mathbf{5}$ are displayed in Figure 4. The complete set of activation barriers for these processes is presented in Table 5 . 


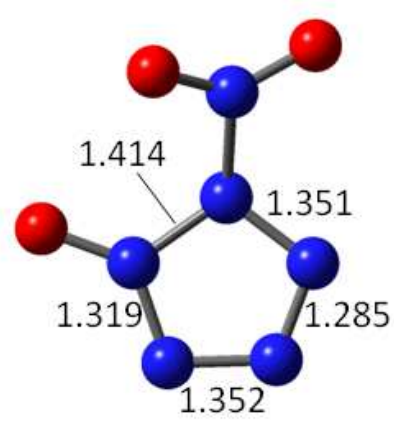

5

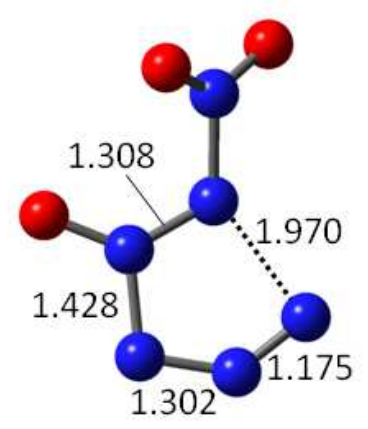

$\mathrm{TS}_{\mathrm{a}}\left(-\mathrm{N}_{2}\right)$

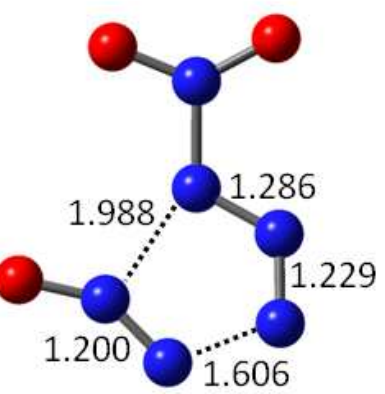

TS $\left(-\mathrm{N}_{2} \mathrm{O}\right)$

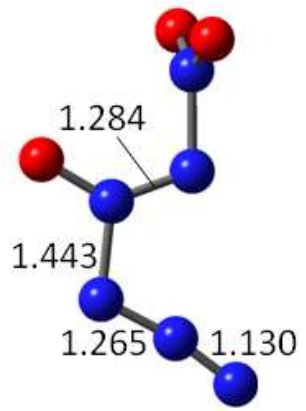

$5 a$

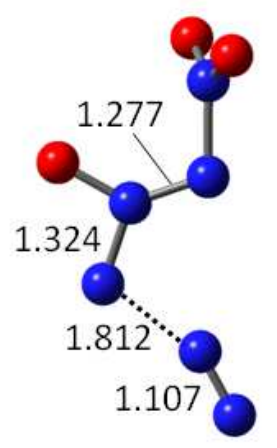

$\mathrm{TS}_{\mathrm{b}}\left(-\mathrm{N}_{2}\right)$

Figure 4. Optimized structures along the paths for $\mathrm{N}_{2}$ elimination (stepwise, top) and $\mathrm{N}_{2} \mathrm{O}$ elimination (concerted, bottom) from $\mathrm{N}_{5} \mathrm{O}-\mathrm{NO}_{2} 5$.

Table 5. Energy barriers toward loss of $\mathrm{N}_{2}$ and $\mathrm{N}_{2} \mathrm{O}$ (in $\mathrm{kJ} / \mathrm{mol}$ ) at the CPCM(acetonitrile)B3LYP/6-311+G(2d,2p)//B3LYP/6-31+G(d) level.

\begin{tabular}{ccc}
\hline Molecule & Loss of $\mathrm{N}_{2}$ & Loss of $\mathrm{N}_{2} \mathrm{O}$ \\
\hline $\mathbf{4}$ & 76 & - \\
$\mathbf{5}$ & $102^{\mathrm{a}}$ & 55 \\
$\mathbf{6}$ & 39 & 122 \\
$\mathbf{8}$ & $128^{\mathrm{a}}$ & $90(98)^{\mathrm{c}}$ \\
$\mathbf{1 1}$ & 65 & 118 \\
$\mathbf{1 2}$ & $\mathrm{b}$ & 62 \\
$\mathbf{1 3}$ & - & 52 \\
\end{tabular}

\footnotetext{
${ }^{\mathrm{a}}$ two step process. Only the largest energy barrier is indicated. ${ }^{\mathrm{b}}$ no TS could be located, even though loss of $\mathrm{N}_{2}$ should be easy, as reflected by its large exothermicity $(-281 \mathrm{~kJ} / \mathrm{mol}) .{ }^{\mathrm{c}}$ value in bracket is computed at the $\operatorname{CCSD}(\mathrm{T}) /$ aug-cc-pVTZ//B3LYP/6-31+G(d) level including CPCM(acetonitrile)-DFT correction.
} 
We find that $\mathrm{N}_{2}$ elimination from 5 involves two consecutive $\mathrm{N}-\mathrm{N}$ bond breaking steps. The associated transition states, $\mathbf{T S}_{\mathbf{a}}$ and $\mathbf{T S}_{\mathbf{b}}$, correspond to energy barriers of 89 and $102 \mathrm{~kJ} \mathrm{~mol}^{-1}$, respectively, with an intermediate structure 5a which is more stable than $\mathbf{5}$ by $8 \mathrm{~kJ} \mathrm{~mol}^{-1}$. Elimination of $\mathrm{N}_{2} \mathrm{O}$ is also possible from $\mathbf{5}$ in a single step, with an energy barrier of $55 \mathrm{~kJ}^{\mathrm{mol}}{ }^{-1}$ making it the most likely fragmentation. Although this barrier confers a reasonable kinetic stability to $\mathbf{5}$, it seems however to be too low to make this product useful in real applications.

These results indicate that $N$-oxide azido-pentazoles $\mathbf{7}$ and $\mathbf{8}$ are kinetically more stable than $N$-oxide nitro-pentazoles 5 and $\mathbf{6}$. It is also clear that the $\alpha$-isomers $\mathbf{5}$ and $\mathbf{7}$ are kinetically more stable than their corresponding $\beta$-isomers $\mathbf{6}$ and $\mathbf{8}$, respectively, even if they are less stable thermodynamically (Table 2). $\mathrm{CCSD}(\mathrm{T})$ calculations for the $\mathrm{N}_{2} \mathrm{O}$ loss from 7 confirm that this azido-pentazole has a sufficient kinetic stability to be an interesting candidate as HEDM material. The effect of an $\mathrm{N}$-oxide moiety on the stability of pentazole derivatives is not as straightforward as that obtained for pentazolates. ${ }^{11}$ Indeed, if the decomposition of azido-pentazole 4 is easier than the decomposition of its mono-oxidized (in $\alpha$ position) derivative $\mathbf{7}$, it is the case neither for the other mono-oxidized (in $\beta$ position) derivative 8 nor for the di-oxidized products 11-13.

\section{Conclusions}

We have explored computationally the reaction paths for the synthesis of $N$ - and $N, N$ '-oxide pentazole-based derivatives. The mechanism for the oxidation by ozone has been determined and the synthesis of some of the mono- and di-oxidized derivatives studied here seems to be realistic, with a regioselectivity in favor of the $\beta$-isomer for the mono-oxidized products. Nitration can be achieved with $\mathrm{NO}_{2}{ }^{+} \mathrm{BF}_{4}^{-}$, whereas azide group addition through electrochemical pathways is not thermodynamically viable. From pentazolate, the most accessible target seems to be $\mathbf{6}$. We recommend a synthesis in two steps from $\mathbf{1}$, with oxidation by ozone followed by nitration. The oxidation of phenylpentazole 15 prior to $\mathrm{N}-\mathrm{C}_{\mathrm{Ph}}$ bond breaking and nitration can also be envisaged. This sequence of reaction, where the second step should be spontaneous, should make possible the use of experimental conditions allowing stabilizing the expected product, despite its weak kinetic stability. Better kinetic stability is observed for azide derivatives however other pathways, like electrophilic transfer of an azido unit with the help of electron-poor sulfonyl azides, should be explored for its formation rather than the electrochemical one studied here. 


\section{Bibliography}

1 R. Engelke, J. Phys. Chem., 1992, 96, 10789-10792.

2 K. O. Christe, Propellants, Explosives, Pyrotechnics 2007, 32, 194-204.

3 V. E. Zarko, Combustion, Explosion and Shock Waves 2010, 46, 121-131.

4 (a) R. J. Bartlett, Chem. Ind. 2000, 4, 140-143 and references therein; (b) S. Fau, R. J. Bartlett, J. Phys. Chem. A 2001, 105, 4096-4106; (c) M. Tobita, R. J. Bartlett, J. Phys. Chem. A 2001, 105, 4107-4113; (d) K. J. Wilson, S. A. Perera, R. J. Bartlett J. Phys. Chem. A 2001, 105, 7693-7699.

5 S. Wallin, H. Östmark, N. Wingborg, P. Goede, E. Bemm, M. Norrefeld, A. Pettersson, J. Pettersson, T. Brinck, R. Tryman, High Energy Density Materials (HEDM) - A literature survey, Swedish Defense Research Agency Report, FOI-R-1418-SE, ISSN 1650-1942, Stockholm, 2004.

6 K. O. Christe, W. W. Wilson, J. A. Sheehy, J. A. Boatz, Angew. Chem. Int. Ed. 1999, 38, 2004-2009.

7 F. Cacace, G. de Petris, A. Troiani, Science 2002, 295, 480-481.

8 A. Vij, J. G. Pavlovich, W. W. Wilson, V. Vij, K. O. Christe, Angew Chem Int Ed. 2002, 41, 3051-3054.

9 H. Östmark, S. Wallin, T. Brinck, P. Carlqvist, R. Claridge, E. Hedlund, L. Yudina, Chem. Phys. Lett. 2003, 379, 539-546.

10 K. D. Colvin, D. L. Strout, J. Phys. Chem. A. 2005, 109, 8011-8015.

11 H. Östmark, H.-G. Ang, Proceedings of the $14^{\text {th }}$ International Detonation Symposium, Coeur d'Alene (Idaho), 2010, pp. 120-125.

12 R. Huisgen, I. Ugi, Angew. Chem. 1956, 68, 705-706.

13 P. Carlqvist, H. Östmark, T. Brinck, J. Phys. Chem. A 2004, 108, 7463-7467.

14 R. N. Butler, J. C. Stephens, L. A. Burke, Chem. Commun. 2003, 1016-1017.

15 M. Rahm, S. V. Dvinskikh, I. Furo, T. Brinck, Angew. Chem. Int. Ed. 2011, 50, $1145-$ 1148 .

16 M. J. Frisch, G. W. Trucks, H. B. Schlegel, G. E. Scuseria, M. A. Robb, J. R. Cheeseman, J. A. Montgomery Jr., T. Vreven, K. N. Kudin, J. C. Burant, J. M. Millam, S. S. Iyengar, J. Tomasi, V. Barone, B. Mennucci, M. Cossi, G. Scalmani, N. Rega, G. A. Petersson, H. Nakatsuji, M. Hada, M. Ehara, K. Toyota, R. Fukuda, J. Hasegawa, M. Ishida, T. Nakajima, Y. Honda, O. Kitao, H. Nakai, M. Klene, X. Li, J. E. Knox, H. P. Hratchian, J. B. Cross, C. Adamo, J. Jaramillo, R. Gomperts, R. E. Stratmann, O. Yazyev, A. J. Austin, R. Cammi, C. Pomelli, J. W. Ochterski, P. Y. Ayala, K. Morokuma, G. A. Voth, P. 
Salvador, J. J. Dannenberg, V. G. Zakrzewski, S. Dapprich, A. D. Daniels, M. C. Strain, O. Farkas, D. K. Malick, A. D. Rabuck, K. Raghavachari, J. B. Foresman, J. V. Ortiz, Q. Cui, A. G. Baboul, S. Clifford, J. Cioslowski, B. B. Stefanov, G. Liu, A. Liashenko, P. Piskorz, I. Komaromi, R. L. Martin, D. J. Fox, T. Keith, M. A. Al-Laham, C. Y. Peng, A. Nanayakkara, M. Challacombe, P. M. W. Gill, B. Johnson, W. Chen, M. W. Wong, C. Gonzalez, J. A. Pople, 2003, Gaussian 03, Revision C.02, Gaussian, Inc, Wallingford CT.

17 (a) M. Göbel, K. Karaghiosoff, T. M. Klapötke, D. G. Piercey, J. Stierstorfer, J. Am. Chem. Soc. 2010, 132, 17216-17226; (b) T. M. Klapötke, D. G. Piercey, J. Stierstorfer, Chem. Eur. J. 2011, 17, 13068-13077.

18 S. G. Van Ornum, R. M. Champeau, R. Pariza, Chem. Rev. 2006, 106, 2990-3001.

19 K. Schank, Helv. Chim. Acta 2004, 87, 2074-2084.

20 (a) G. A. Olah, S. J. Kuhn, Chem. Ind. (London) 1956, 98; (b) G. A. Olah, S. J. Kuhn, A. Mlinko, J. Chem. Soc., 1956, 4257-4258; (c) S. J. Kuhn, G. A. Olah, J. Am. Chem. Soc., $1961, \mathbf{8 3}, 4564-4571$.

21 G. A. Olah, in Chemistry of Energetic Materials, ed. G. A. Olah and D. R. Squire, Academic Press, 1991, pp. 139-204.

22 I. V. Tselinskii, S. F. Mel'nikova, S. A. Fedotov, Russian Chem. Bull., 2002, 51, 14661467.

23 M. T. Nguyen, T.-K. Ha, Chem. Phys. Lett., 2001, 335, 311-320.

24 D. A. Dixon, D. Feller, K. O. Christe, W. W. Wilson, A. Vij, V. Vij, H. D. B. Jenkins, R. M. Olson, M. S. Gordon, J. Am. Chem. Soc., 2004, 126, 834-843.

25 R. L. Jackson, M. J. Pellerite, J. I. Brauman, J. Am. Chem. Soc., 1981, 103, 1802-1805. 